\title{
Development of graphic formulas for the depiction of familiar objects
}

\author{
Delphine Picard \\ University of Montpellier III, France \\ Annie Vinter \\ LEAD/CNRS, University of Bourgogne, Dijon, France
}

\begin{abstract}
We investigated the nature of graphic formulas in 5-, 7-, and 9-year-old children when they were asked to draw a house and a television in a free condition, and then to draw from photographs of these objects. Assuming that the frequency of occurrence of a feature in children's drawings reflects its semantic weight, we studied the relations between occurrence and order of production of features to assess the extent to which a core-to-periphery progression principle (van Sommers, 1984) applies to the graphic formulas. The results showed that this principle was essentially present in the free drawing context. Under copying conditions, the order of production of the features was under the influence of perceptual and geometric factors, which elicited the production of subsystems of features at the depends of the application of the core-to-periphery progression principle. In the free condition, the core-to-periphery principle was mostly relevant in accounting for graphic formulas of the house in the young children ( 5 and 7 years), and of the television at ages 7 and 9 . We suggest that the development of a graphic formula is partially related to the development of the object as a category in the child's conceptual system.
\end{abstract}

\section{Introduction}

Among the many approaches used to study drawing behaviour, one in particular distinguishes between what has been referred to as the "syntax" and the "semantics" of drawing (see, e.g., van Sommers, 1984). The syntactic level deals with how drawing movements are organised and ordered in a sequence, while the semantic level refers to what is depicted in terms of symbolic content. These two levels are defined in analogy with the classical distinction in language between syntagmatic (horizontal) organisation and paradigmatic (vertical) organisation. The syntagmatic dimension emphasises the sequential structure of language utterances; in the graphical field, it parallels movement sequence production. The paradigmatic dimension is associated with the availability of a number of linguistic candidates (words for instance) at any point of a produced sequence; in drawing, there is also a range of graphic units (or primitives, van Sommers, 1984), available for the depiction of objects or scenes.

However, the analogy between drawing and language is limited because a one-to-one correspondence between syntactic and semantic features of drawing and language does not exist. The graphic primitives (e.g., a segment of a line or a cluster of dots) have no semantic status on their own: It is the context or the whole picture that determines their meaning (see Arnheim, 1964). Although graphic rules have been defined to account for the local aspects of the drawing syntax (see Goodnow \& Levine, 1973), one cannot assume that these rules form a grammar analogous to the learned grammar of language. The distinction between semantics and syntax for drawing may be construed as a way to distinguish between the "what" (what is depicted) and the "how" (how it is done) of drawing. This is in this general sense that we refer to this distinction, the aim of the paper being to show that both levels are tightly connected in the development of graphic formulas.

A "grammar of action" (Goodnow \& Levine, 1973; Simner, 1981; van Sommers, 1984) was defined to account for the formal and executive constraints of drawing. The production of simple geometrical patterns (e.g., a square) is guided by of set a graphic rules that specify where to start (preferentially at the top-left and with a vertical segment) and how to progress (top-to-bottom, left-to-right, threading and anchoring one segment to a previous one) in the drawing. Developmental trends have been reported in the way that these rules are adhered to (Nihei, 1983; Ninio \& Lieblich, 1976; Thomassen \& Teulings, 1979; Vinter, 1994). Intimately linked to the architecture of the motor system, most of these rules seem to be motivated by economy, since their application reduces the cost of movement planning and execution.

The drawing syntax devoted to the copying of simple geometrical patterns has also been shown to vary as a function of the meaning attributed to the pattern in adults as well as in children (van Sommers, 1984; Vinter, 1999). In these studies, participants had to reproduce perceptually ambiguous drawings to which two different meanings could be attributed (e.g., a pyramid and its reflection versus a diamond crossed by a line). Results showed that drawing behaviour was, to a certain extent, permeable to meaning, so that the participants modified their drawing syntax in a way determined by the model's meaning. According to van Sommers (1984), the drawing syntax emerges from a cooperation or a competition from two main forces: One acting in a "bottom-up" 
direction-the geometrical and formal executive constraints of drawing - and the other one in a "top-down" direction-the semantic force. The semantic force may determine stroke ordering by imposing a particular segmentation of the model to be drawn. From a developmental point of view, Vinter (1999) showed that as long as the two forces did not conflict, even young children were open to semantic influences. However, if a conflict arose, the geometrical and formal executive factors took priority over semantic influences in young children, while the reverse occurred in older children.

How children proceed in the drawing of familiar categories of objects, such as a man or a house, has been defined in terms of "graphic formulas", in order to account for the stable sequencing of the movements involved in the production of a drawing. However, drawing behaviour at the syntactic level cannot be thought of as a "compiled procedure" as initially suggested by Karmiloff-Smith (1990) and then revised (Karmiloff-Smith, 1992, 1999). As pointed out by Spensley and Taylor (1999), a compiled procedure is a very rigid and fixed sequence of commands, re-coded for speed of execution. Numerous experimental data have provided evidence countering the idea that drawings were produced by executing compiled procedures (Spensley \& Taylor, 1999). Nevertheless, drawing behaviour at the syntactic level displays sufficient stability with respect to the sequence of actions, so that graphic formulas or "routines" are involved in the portrayal of familiar objects. Stiles (1995) has shown that very young children (aged between 2 and 3 years) already used graphic formulas in their free drawings when they depicted specific objects. Zhi, Thomas, and Robinson (1997) have shown that young children use relatively fixed sequences to produce familiar drawings. Using a free drawing task of a postman and a Father Christmas, the authors recorded the sequence in which head, trunk, arms, and legs were drawn by a group of children aged 3 to 5 years. The results indicated that 25 out of the 32 children followed exactly the same sequence of steps for their two drawings of the human figures. Similar results were found by Barlow, Jolley, White, and Galbraith (2003) in a repeated free drawing task of a frequently drawn object (the human figure) by 4-, 6-, and 8-year-old children. The drawings were examined for the pairs of elements that were drawn together in the same order throughout all three drawings. Results indicated that $40 \%$ of the children used the same sequence of production across the three human figure drawings, whatever their age. However, when children were examined for the repeated drawing of a not frequently drawn object (a cracker), conservatism in sequence production order was low, suggesting that a graphic formula was not yet established for this object.

Van Sommers (1984) has offered an interesting account of the notion of graphic formula in young children. In a free drawing task involving familiar objects, this author conducted a detailed examination of 5- and 6-year-old children's graphic formulas with respect to movement sequence and stroke production. He reported that when children drew one object several times from memory, they consistently maintained their style, that is to say, the global appearance of their drawings. The sequence of the representational features of an object was highly structured and fairly stable. The children, however, did not adhere to a standard motor routine, as can be seen in the high variability of their stroke production.

Van Sommers has shown that three main principles characterised the graphic formulas: an accretion principle (tendency to draw new parts on already-drawn ones), a coreto-periphery progression principle (tendency to draw core features prior to peripheral ones) and a subsystem elaboration principle (tendency to draw geometrically and semantically linked representational units in sequence). The accretion principle is a very basic principle of drawing by which children (and adults) progress in a natural and coherent fashion for drawing parts of an object. When drawing a man, for instance, the order of production of the different parts of the man follows a natural logic by which a new part tends to be drawn (accreted) on the basis of an already drawn one. The core-toperiphery progression principle is much more semantic in nature in that core features (i.e., parts of an object that are necessary to define its identity) tend to be produced before more peripheral features (i.e., parts of an object whose presence is not fundamental to the identification of the object). For instance, head, trunk, arms, and legs tend to be produced before more peripheral parts such as hair, teeth, shoes, and so on. The subsystem elaboration principle results from influences of both the accretion principle (mainly geometric in nature) and the core-to-periphery progression principle (mainly semantic in nature). For instance, some peripheral features (e.g., hair) may be directly drawn after a core feature of the object (head) while other core features have still not been drawn (e.g., trunk). This promising perspective concerning graphic formulas introduced by van Sommers (1984) has, however, never been systematically tested within a developmental approach.

In our view, the core-to-periphery progression principle suggests that a graphic formula may, in part, develop as a function of how the object is represented as a category in the conceptual system. It has been shown that children build privileged representations of objects or prototypical mental schemas from the abstraction of the central tendencies of objects pertaining to one category (Cordier, 1993). In these privileged representations, the object appears in a canonical position (Palmer, Rosch, \& Chase, 1981) and its properties can be organised as a function of their "weight" or "relief" (Le Ny, 1979), some of them defining the core or central properties of the object, others being more peripheral. If we consider that children's free drawings reflect, more or less directly, privileged mental representations of objects, it can be assumed that the internal organisation of the object's properties in terms of semantic weight plays an important role in the sequencing of the representational features within the graphic formulas.

In the present study, we investigated graphic formulas displayed by 5 - to 9 -year-old children in a free drawing task and in a copying task involving two different objects, a house and a television. We focused on children's syntactic behaviour, considering both global (features sequencing) and local (actions related to start positions, direction, and threading) aspects of children's syntactic behaviour. We selected children aged at least 5 years because these children are known to have reached behavioural mastery in the drawing of familiar objects, at least for the house (see Karmiloff-Smith, 1992). We used a house and a television because both are familiar objects for children, and their drawing does not constitute a difficult graphic task, though one (the house) is probably more frequently drawn by children than the other. These objects also differ in terms of number of features that their graphical representation can include; these are less numerous in the television. 
An analysis of the content of the drawings was conducted to provide cues about the semantic weight of each feature, considering that the more frequent a feature, the more important it is for defining the identity of the depicted object. The application of the core-to-periphery progression principle was studied throughout the relations between the percentage of occurrence of the different features of objects and their respective order of appearance in the drawing process. When this principle is applied, a systematic relation should be observed between the two variables. We hypothesised that, in the free drawing condition, graphic formulas describing the television should be less organised than those describing the house with regard to the application of the core-to-periphery progression principle, especially in young children. Graphic rules (starting rules, direction rules, threading) should highly structure the drawing process.

Following the free drawing task, a copying task was introduced to test the extent to which a similar drawing process sustained children's graphic formulas when photographs of real objects were provided as models. The two tasks differ in the sense that, in the free drawing task, children are in a creative mode while in the copying task, they have to consider the specific and visual properties of the models. We hypothesised that the core-to-periphery progression principle should also apply to the drawing processes in the copying task, although to a lesser extent than that observed in the free drawing task. Indeed, in the copying task, the order of production of the features should be under the influence of perceptual and geometric factors, which could elicit the production of subsystems of features at the depends of the application of the core-to-periphery progression principle. The application of the graphic rules (starting positions, starting direction, and threading) should be relatively high when a model is available.

\section{Method}

\section{Participants}

Fifty-four right-handed children volunteered to participate in the experiment. They were divided into 3 age groups of 18 children each: 5 years (age range $=4$ years 11 months to 5 years 9 months, mean age $=5.3$ years, 9 girls and 9 boys), 7 years (age range $=7$ years 1 month to 7 years 9 months, mean age $=7.4$ years, 9 girls and 9 boys), and 9 years (age range $=9$ years 2 months to 9 years 10 months, mean age $=9.4$ years, 10 girls and 8 boys). None of these children was ahead or behind with respect to schooling or had any psychomotor deficits with drawing and handwriting. Their vision was normal or corrected to normal. Children were essentially from middle SES families. They were observed individually in a quiet room inside their school, with both active parental consent and assent.

\section{Material}

Two colour photographs (size: $15 \times 10 \mathrm{~cm}$ ) of a house and a television were used as models in the copying condition (see Figure 1). They were complex models of real-life objects. The house was typical of the Burgundy area. We deliberately selected these complex models to force children to consider a large number of object features in their drawing. Furthermore, in the copying condition, drawing from photos of real objects were preferred to $2 \mathrm{D}$ line-drawings; this is because the greater constraints imposed by the former condition make it closer to the free-drawing condition in terms of task demands (Cox, 1992). A detailed observation of the photographs shows that the house included 23 features and the television 11 features (see Figure 1). The children produced their drawings on separate white paper sheets (size: $21 \times 14.8 \mathrm{~cm}$ ) using a normal pen.

\section{Procedure}

The children were asked to produce drawings of the two objects in two successive tasks. The first task (free drawing task) required them to draw the selected objects under evocation, that is to say without any model at their disposal but in response to verbal naming. We simply asked them "you know how to draw houses (televisions), don't you? I would like you to make a nice drawing of a house (television) for me, as you know to do it". When the child considered the task to be complete, the experimenter turned to the next item. Once the free drawing task was completed, the participants had to draw the same objects under copying conditions (copying task), with the photographs as models. The two tasks were always presented in this order, free drawing task then copying task: The first task provided comparison data used for the analysis of the data obtained in the second task. There was no break between the two tasks, and the children were not told that they were going to make a copy of the two objects until they had completed the free drawing task. The copying instructions required them to attentively examine the model and to reproduce it as accurately as possible. The precise instructions were: "Look, this is photograph of a house (television). Look very carefully at this house (television), and try to draw exactly all that you see of this house (television). Take your time and make the best drawing you can. Don't forget to look carefully at the model". When the child considered the task to be complete, the experimenter turned to the next item. Afterwards, children were asked to comment about their productions in the copying task, namely what they drew from the models. The order of the objects to be drawn was counterbalanced across children for each task. In each age group, half of the children ( 4 girls and 5 boys or 5 girls and 4 boys) were asked to produce a house and then a television under the free drawing condition, the objects being presented in the same order in the copying condition. The other half of the children were presented the two objects in a reverse order (television, then house) for both tasks. The experiment was completed on an individual basis and lasted between 8 and 20 minutes, depending on the child. A second experimenter was trained to code online the starting points, the direction of the drawing actions, and the order in which the segments were drawn. Moreover, the complete experimental session was videorecorded for each child. The online coding of the children's drawing sequences was checked off-line on the basis of the video recordings by an independent judge. Only a few errors were detected $(3.1 \%)$ and they were corrected before the analysis of the data.

\section{Data analysis}

A content analysis of the drawings was made, focusing on the graphical features included in the drawings. Considering the overall set of data for the free drawing task, 15 features were produced in the house condition: body (bo), roof (ro), 


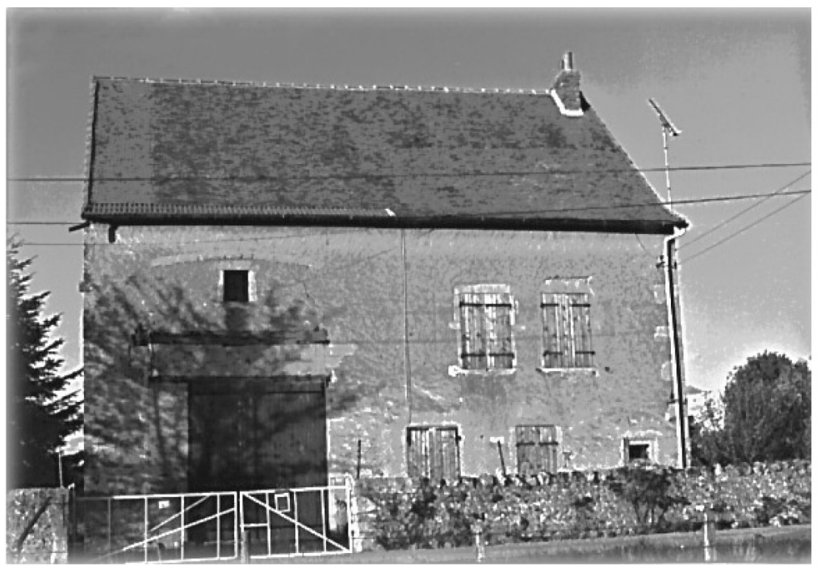

House Model

Components list $(n=23)$ :

- body (bo),

- roof (ro),

- door (do),

- hinges of door (d1),

- beam of door (d2),

- right upstairs window (ruwi),

- left upstairs window (luwi),

- right downstairs window (rdwi),

- left downstairs window (ldwi),

- hinges of windows (ruwi1, luwi1, rdwi1, ldwi1),

- frame of windows (ruwi2, luwi2, rdwi2, ldwi2),

- chimney (chi),

- aerial (ae),

- gutter (gu),

- beam (be),

- right downstairs opening (rdo),

- left upstairs opening (luo).

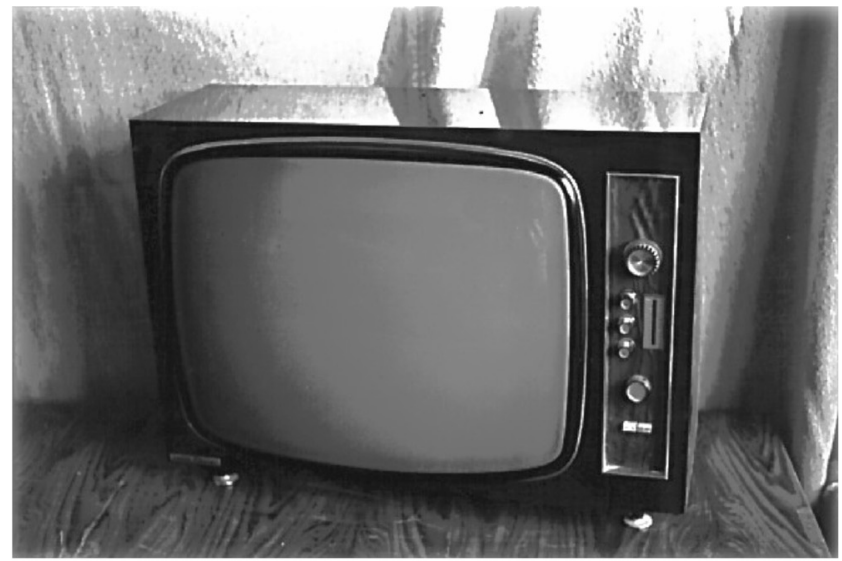

Television Model

Components list $(n=11)$ :

- body (bo),

- screen (s),

- dial (di),

- knob 1 (k1),

- knob 2 (k2),

- knob 3 (k3),

- knob 4 (k4),

- knob 5 (k5),

- frequency knob (fk),

- switch (sw),

- support (su).

Figure 1. Photographs of a house and a television used as material in the experiment (the originals were in colour and twice the size). Features lists are mentioned for each model.

windows left and right (lwi, rwi), window panes (lwi1, rwi1), window shutters (lwi2, rwi2), window curtains (lwi3, rwi3), door (do), door handle (do1), chimney (chi), smoke (chil), and aerial (ae). Seven features were produced in the television condition: body (bo), knob (k), channel (ch), screen (s), dial (di), aerial (ae), and support (su). For the copying task, the number of drawn features was 21 for the house and 11 for the television (see Figure 1). Two of the 23 features of the house model (rdwi2 and ldwi2) were never produced in the overall set of children's drawings, while all the 11 defined features of the television were. Of course, not all the features appeared in each individual drawing. Figure 2 provides illustrations of drawings made under free and copying conditions. Verbal comments produced by the children were used to determine the nature of the drawn features under copying condition in cases of ambiguity (they were very rare, however; $n=4 / 108$ drawings). We first examined the number of drawn features of the house and television in the drawings obtained in the free and copying tasks, to get a quantitative measurement of the semantic content of the drawings. We then examined the kinds of features that were present at high and low frequencies in the drawings as a function of age and task, to get a more qualitative assessment of the semantic content of the drawings. The percentages of occurrence of the overall set of features ranged from $6 \%$ to $100 \%$ in the free and copying tasks. These percentages could directly inform us about the status of the features for a given graphic representation: The more frequent a feature was, the greater its weight for a given graphic representation. Two judges (undergraduate students, naïve to the aims of the study) working independently made the content analyses. They first listed the various features found in the entire set of drawings of each object (it was explained to them that the body or roof of a house, for instance, are features, as well as a door handle or tiles). A complete agreement was obtained in the constitution of the lists. Then they coded the presence or absence of each feature in the children's drawings. The inter-judge agreement was high, 97.4\%, and Kappa coefficient for inter-rater reliability was $.98, p<.01$. The few disagreements obtained were settled by discussion.

A process-oriented analysis of the drawing was also made, focusing on the sequential characteristics of the drawing actions. This analysis was intended to determine whether there were some fixed aspects in the way that the children parsed and ordered the features of their drawings. To this end, individual drawing syntaxes were encoded in terms of feature order list (e.g., 1-bo, 2-ro, 3-chi, 4-wi, 5-wi1, 6-do, 7-do1), where the numbers identify the order of appearance in the drawing and the letters the features (see Figure 2). Note that, once engaged in drawing one feature, most of the children completed it in its entirety before drawing another feature of 


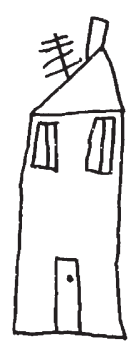

House (Free) 5 yrs

1- bo, 2-ro,

3- do, 4- do1,

5- lwi, 6-lwil,

7- rwi, 8-rwil,

9- chi, 10- ae

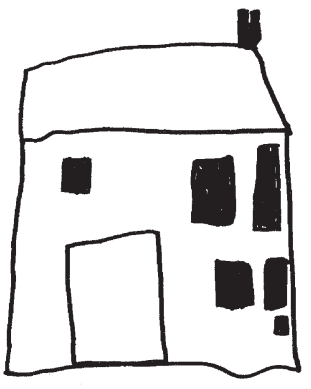

House (Copy) 5 yrs

1- bo, 2-ro,

3- do, 4- luwi,

5- ruwi, 6- ldwi,

7- rdwi, 8- luo,

9- rdo, 10-chi

House (Copy) 7 yrs

1- bo, 2- ro, 3- chi,

4- do, 5- ldwi,

6- rdwi, 7-dwil,

8- luwi, 9- ruwi,

10- luo, 11- ae
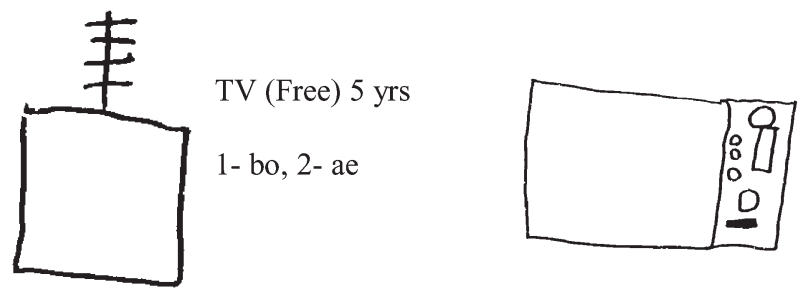

TV (Copy) 5 yrs

1- bo, 2- di, 3- k1,

4- k2, 5- K3, 6- k4,

7- fk, 8- k5, 9- sw

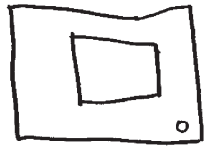

TV (Free) 9 yrs

1- bo, 2- s, 3-k

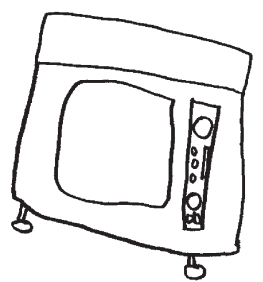

TV (Copy) 9 yrs

1- bo, 2- di, 3- k1,

4- k2, 5- k3, 6- k4,

7- fk, 8- k5, 9- sw,

10- s, 11- su

Figure 2. Illustrations of drawings of the house and television produced under free and copying conditions. Feature production order is mentioned for each drawing.

the object. We first adopted van Sommers' mode of representation of the relation between the percentages of occurrence of features and their mean temporal order of appearance in the individual drawing sequences (van Sommers, 1984, pp. 212-213), because it provides a clear description of the structure of the data. Such a description of the data allows us to assess whether the core-to-periphery progression principle could be applied to the drawing sequences. We also investigated the application of the graphic rules and the conservation, from the free drawing task to the copying task, of the actions involved in the production of the most regularly drawn features of objects. The highly frequent features (80-100\%), designated as "core features" henceforth, and present in both tasks, included body, roof, door, and windows of the house, and body of the television. Four rules were checked for each core feature, starting top, starting left, with a vertical (coded 1 when applied, 0 when absent) and threading, measured by the number of pen-lifts ( 3 maximum for a rectangle). Moreover, for each rule and feature, action conservation was coded 1 when, in both tasks, children similarly applied/or didn't apply the graphic rule. The other cases were coded 0 . Two judges (two naïve undergraduate students) working independently made the process-oriented analyses. The inter-judge agreement was $98.8 \%$, and Kappa coefficient for inter-rater reliability was $.99, p<.01$.

\section{Results}

\section{A content analysis of the drawings produced in the different tasks: What is drawn?}

Table 1 presents the evolution with age of the mean number of features per object and task. A 3 (age) $\times 2$ (object) $\times 2$ (task) mixed analysis of variance (ANOVA) with both object and task as within-subjects factors, and age as a between-subjects factor, was performed on the mean number of drawn features ${ }^{1}$. We

${ }^{1}$ The same analysis of variance was also performed with relative frequencies rather than number of features as a dependent variable. The relative frequencies were calculated as the number of drawn features divided by the maximum number of features ( $n=15$ for the free house drawing, $n=7$ for the free television drawing, $n=21$ for the copied house, and $n=11$ for the copied television). Results obtained were identical to those reported in terms of number of drawn features. 
Table 1

Mean number of drawn features (SD) by age, object, and task

\begin{tabular}{lcccrrr}
\hline & \multicolumn{3}{c}{ House } & & \multicolumn{2}{c}{ Television } \\
\cline { 2 - 3 } Age & Free & Copying & & Free & Copying & \multirow{2}{*}{ Mean } \\
\hline 5 years & $7.56(2.36)$ & $7.94(2.04)$ & & $2.06(0.54)$ & $8.28(1.60)$ & $6.46(1.63)$ \\
7 years & $7.94(1.80)$ & $12.20(3.54)$ & & $3.22(0.73)$ & $9.72(1.67)$ & $8.27(1.93)$ \\
9 years & $7.61(2.27)$ & $12.90(2.36)$ & & $3.39(0.77)$ & $10.20(0.56)$ & $8.52(1.49)$ \\
Mean & $7.70(2.14)$ & $11.01(2.64)$ & & $2.89(0.68)$ & $9.40(1.27)$ & $7.75(1.68)$ \\
\hline
\end{tabular}

The maximum number of features observed for the house was 15 in the free task and 21 in the copying task; for the television it was 7 and 11 respectively.

Table 2

Distribution of the features of the house and television drawn by each age group in the free drawing task across four ranges of occurrence

\begin{tabular}{|c|c|c|c|c|}
\hline & $\begin{array}{c}\text { Core } \\
80-100 \%\end{array}$ & $\begin{array}{c}\text { Periphery I } \\
60-79 \%\end{array}$ & $\begin{array}{c}\text { Periphery II } \\
20-59 \%\end{array}$ & $\begin{array}{c}\text { Periphery III } \\
0-19 \%\end{array}$ \\
\hline \multicolumn{5}{|l|}{ House } \\
\hline 5 years & bo, ro, do, lwi, rwi & do1 & chi, chi1, lwi1, rwi1 & ae, lwi2, rwi2, lwi3, rwi3 \\
\hline 7 years & bo, ro, do, lwi, rwi & do1, chi & chi1, lwi1, rwi1 & ae, rwi2, lwi3, rwi3 \\
\hline 9 years & bo, ro, do, lwi, rwi & do1 & chi, lwi1, rwi1 & lwi2, rwi2, lwi3, rwi3 \\
\hline \multicolumn{5}{|l|}{ Television } \\
\hline 5 years & bo & $\mathrm{k}, \mathrm{s}$ & di, ae & \\
\hline 7 years & bo, $\mathrm{k}$ & di, s, ae & $\mathrm{ch}$, su & \\
\hline 9 years & bo & $\mathrm{k}, \mathrm{s}$ & di, ae & $\mathrm{ch}, \mathrm{su}$ \\
\hline
\end{tabular}

checked that sex as a between-subjects factor did not yield significant effects $(p s>.20)$.

Children globally drew more features with increasing age, $F(2,51)=18.92, M S E=4.90, p<.001$, a significant increase in the number of drawn features being obtained between 5 and 7 years of age (post hoc Scheffé test, $p<.01$ ), not between 7 and 9 years (post hoc Scheffé test, $p=.78$ ). Features were more numerous in the copying task than in the free drawing task, $F(1,51)=377.60, M S E=3.47, p<.001$, but a significant age by task interaction was obtained, $F(2,51)$ $=10.84, M S E=3.47, p<.001$. This interaction revealed that the increase between 5 and 7 years of age in the number of drawn features occurred only in the copying condition (post hoc Scheffé test, $p<.01$ ), not in the free drawing context (post hoc Scheffé test, $p=.68$ ). Moreover, at 7 and 9 years, the number of features was much higher in the copying task than in free drawing, in comparison to the youngest children (post hoc Scheffé tests, $p<.01)$. The age by object by task interaction was also significant, $F(2,51)=10.39, M S E=2.33, p<.001$. Results showed that the increase in the number of drawn features between 5 and 7 years of age occurred only for the copying of the house model (post hoc Scheffé test, $p<.01$ ), not for the copying of the television (post hoc Scheffé test, $p=$ .70 ). Note that no ceiling effect could have occurred here because the television model included at least 11 features and the children reproduced only 9 on average. In the free drawing task, the increase of the number of drawn features with age was not significant whatever the object (post hoc Scheffé tests, $p>$ $.80)$. Finally, 5-year-old children did not produce significantly more features of the house in the free and in the copying tasks (post hoc Scheffé test, $p>.90$ ), whereas older children did (post hoc Scheffé test, $p<.01$ ). By contrast, the copying of the television model evidenced more features than the free drawing of this object at any age (post hoc Scheffé test, $p<$ $.01)$.

Table 2 shows the distribution of the features of the house and the television drawn by each age group across four ranges of occurrences $(0-19 \%, 20-59 \%, 60-79 \%, 80-100 \%)$ in the free drawing condition. Table 3 reports the results obtained in the copying condition. These intervals of frequencies (respectively labelled as periphery III, periphery II, periphery I, and core) were defined in order to descriptively check whether the resulting classification of the drawn features was stable across ages or not.

A remarkable age-related stability of the distribution of the features across the ranges of occurrence appeared in the free drawing task (see Table 2). The core features of the house included four elements whatever the age of the subject, i.e., body (bo), roof (ro), door (do), and windows (lwi, rwi); for the television, only one feature was core, the body (bo), to which a knob (k) was added at age 7 . For the house, the first peripheral feature $(60-79 \%)$ was the door handle (do1), to which the chimney (chi) was added at 7 years. Moreover, the next peripheral region consisted of the same features, the chimney (chi) with smoke (chi1), and the window panes (lwi1, rwi1), as did the final ones: window shutters (rwi2, lwi2) and curtains (rwi3, lwi3) (also aerial [ae] at 5 and 7 years). The same types of results were observed for the television, though the drawings produced by the youngest children contained fewer features and these were drawn less frequently. Spearman rank correlations were computed between the percentages of occurrence of the house or television features produced at 5 and 7 years, 5 
Table 3

Distribution of the features of the house and television drawn by each age group in the copying task across four ranges of occurrence

\begin{tabular}{|c|c|c|c|c|}
\hline & $\begin{array}{c}\text { Core } \\
80-100 \%\end{array}$ & $\begin{array}{l}\text { Periphery I } \\
60-79 \%\end{array}$ & $\begin{array}{l}\text { Periphery II } \\
20-59 \%\end{array}$ & $\begin{array}{c}\text { Periphery III } \\
0-19 \%\end{array}$ \\
\hline \multicolumn{5}{|l|}{ House } \\
\hline 5 years & bo, ro, do, ruwi, luwi & ldwi, rdwi, chi & luo, rdo & $\begin{array}{l}\text { ruwi1, luwi1, rdwi1, } \\
\text { ldwi1, do1, gu, ae }\end{array}$ \\
\hline 7 years & $\begin{array}{l}\text { bo, ro, do, ruwi, luwi, } \\
\text { rdwi, luo }\end{array}$ & ldwi, ruwi, luwi, chi & $\begin{array}{l}\text { rdwil, ldwil, do1, do2, } \\
\text { rdo, be, gu, ae }\end{array}$ & ruwi2, luwi2 \\
\hline 9 years & $\begin{array}{l}\text { bo, ro, do, ruwi, luwi, rdwi, } \\
\text { luo, ldwi, chi }\end{array}$ & ruwi1, luwi1, be & rdwil, ldwil, do1, rdo, gu, ae & do 2 \\
\hline \multicolumn{5}{|l|}{ Television } \\
\hline 5 years & bo, sw, k1, k2, k3, k4 & di, $\mathrm{k} 5$ & $\mathrm{fk}, \mathrm{s}$ & $\mathrm{su}$ \\
\hline 7 years & bo, sw, k1, k2, k3, k4, & $\mathrm{s}$ & $\mathrm{su}$ & \\
\hline 9 years & $\begin{array}{c}\mathrm{k} 5 \text {, fk, di } \\
\text { bo, sw, k1, k2, k3, k4, k5, fk, di, s, su }\end{array}$ & & su & \\
\hline
\end{tabular}

and 9 years, and 7 and 9 years. For the house, the correlations were $.96(p<.01, n=14$ features) between 5 and 7 years, and $.94(p<.05, n=13$ features) between 7 and 9 years. For the television, the correlations were $.70(p=.19, n=5$ features) between 5 and 7 years, and $.89(p<.01, n=7$ features) between 7 and 9 years.

The copying condition induced more differences (see Table 3). The core features of the house remained the same as in the free condition at age 5, with two more features being added at age 7 (right downstairs window [rdwi] and left upstairs opening [luo]) and also at age 9 (left downstairs window [ldwi] and chimney [chi]). The same profile of results characterised the peripheral features. With increasing age, they tended to become less numerous in the most peripheral regions of occurrence. However, globally, the same order of features was observed at all ages when they were ranked according to their percentages of occurrence. The Spearman rank correlations were $.93(p<.01, n=17$ features) between 5 and 7 years, and $.90(p<.01, n=19$ features) between 7 and 9 years. For the television, in contrast, we observed a large increase in the number of very frequently drawn features in the copying task, still higher at 9 than at 5 years. However, these features were the same across ages: body (bo), switch (sw) and knobs (k1, $\mathrm{k} 2, \mathrm{k} 3, \mathrm{k} 4$ ) at 5 years, completed by a dial (di) and other knobs $(\mathrm{k} 5, \mathrm{fk})$ at 7 years, and by a screen (s) at 9 years. Although more variability occurred with the peripheral features, there were also comparatively fewer of these for the television than for the house. Spearman rank correlations were not significant between 7 and 9 years ( $r=.47, p=.14, n=11$ features), but reached a significant level between 5 and 7 years $(r=.86, p<$ $.01, n=11$ features).

\section{A process-oriented approach to drawing: How did the children proceed?}

Figure 3 presents the relations between the percentages of occurrence of features and their mean order of appearance in the drawing sequence for the house drawn in the two tasks and Figure 4 displays those related to the television (see Appendix A for the full set of the data).

As reported by van Sommers (1984), we also observed for the house drawing (Figure 3), a fairly systematic relationship between the degree of salience of a feature and how early it was drawn: The more frequent a feature was, the earlier it was drawn. Spearman rank correlations, computed between percentages of occurrence and mean ranks of appearance of the house features, were significant at age 5 in the free drawing condition ( $r=-.61, p<.05, n=15$ features), as well as at age 7 ( $r=-.60, p<.05, n=14$ features), and only marginally significant at age $9(r=-.46, p=.09, n=14$ features). In the copying condition, Spearman rank correlations between percentages of occurrence and mean ranks were significant at age $5(r=-.60, p<.05, n=17$ features), as well as at age $7(r$ $=-.59, p<.01, n=21$ features $)$, but not at age $9(r=-.38, p$ $=.10, n=19$ features). For the television drawing, Figure 4 shows that the relation between percentages of occurrence and mean production ranks were relatively good at age 7 and 9 in the free drawing condition, but not in the youngest children, who displayed few features for drawing this object. Spearman rank correlations were significant at ages 7 and $9(r=-.75, p=$ $.05, n=7$ features for both ages), but not in the youngest age group ( $r=-.22, p=.72, n=5$ features). In the copying condition, the correlations between percentages and mean ranks of the television features were not significant, whatever the age (5 years: $r=-.39, p=.23, n=11$ features; 7 years : $r=$ $-.48, p=.13, n=11$ features ; 9 years: $r=-.15, p=.66, n=$ 11 features).

Comparing Figure 3 and Figure 4 showed important differences in terms of clusters of features for the two objects, especially in the copying task. These differences are likely to reveal that the television model was not as complex as that of the house, so that even young children were able to produce the whole set of features $(n=11)$ with a relatively high frequency. By contrast, this was not the case for the house model, for which a large number of features were drawn at varied frequencies. The difference between Figure 3 and Figure 4 was less pronounced in the free drawing condition, the pattern of results for the television being globally more spaced out than that of the house due to a lower number of features.

Analysing further the way that features were linked in sequence in the children's drawings showed that, in the freedrawing task, a recurrent sequence organised the core features of the house from 5 to 9 years of age, "body $->$ roof $->$ windows $<->$ door", thus forming a minimal version of the object to which the children anchored the other features, which were more peripheral with regard to the category. Moreover, 
5 yr-house-free

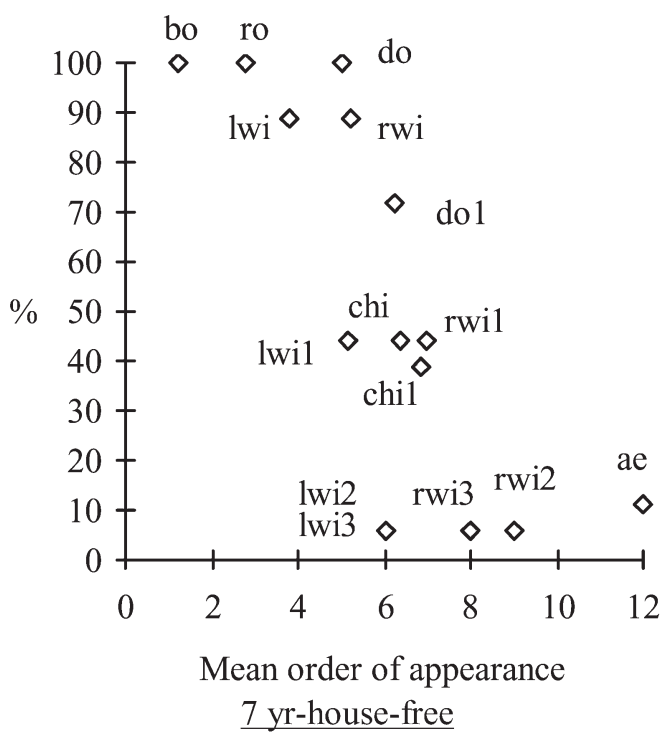

bo ro

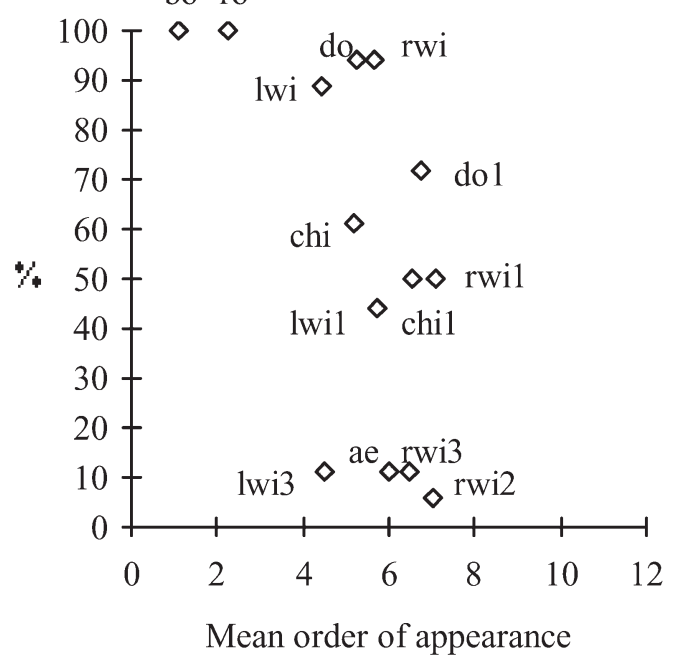

9 yr-house-free

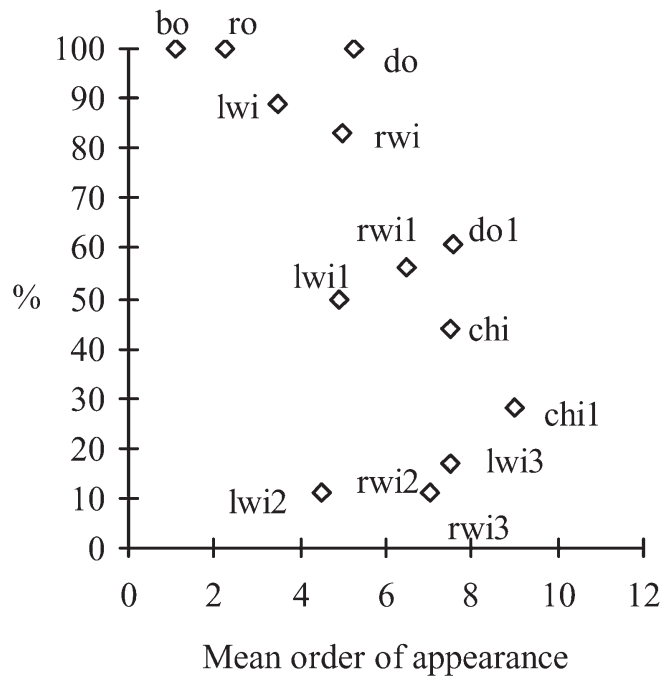

$\underline{5 \text { yr-house-copy }}$

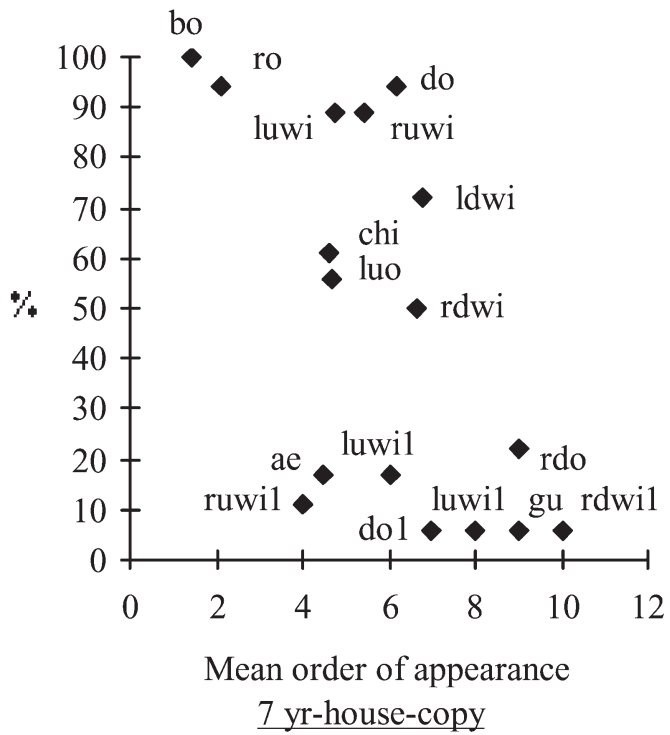

bo ro luwi ruwi do
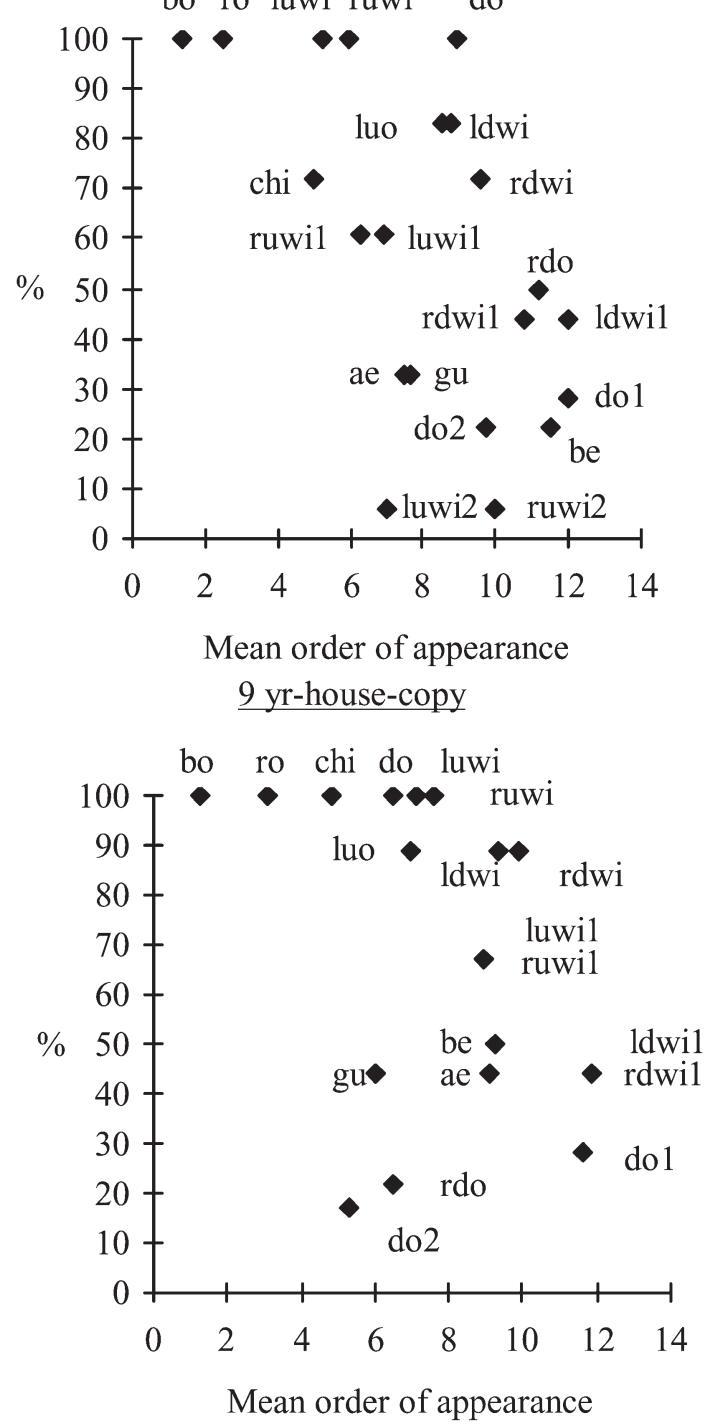

Figure 3. Relation between percentages of occurrence of the features of the house and their mean order of appearance in the drawing sequences per age group and task (see Appendix A for full data). 


\section{$\underline{5 y r-T V-f r e e}$}

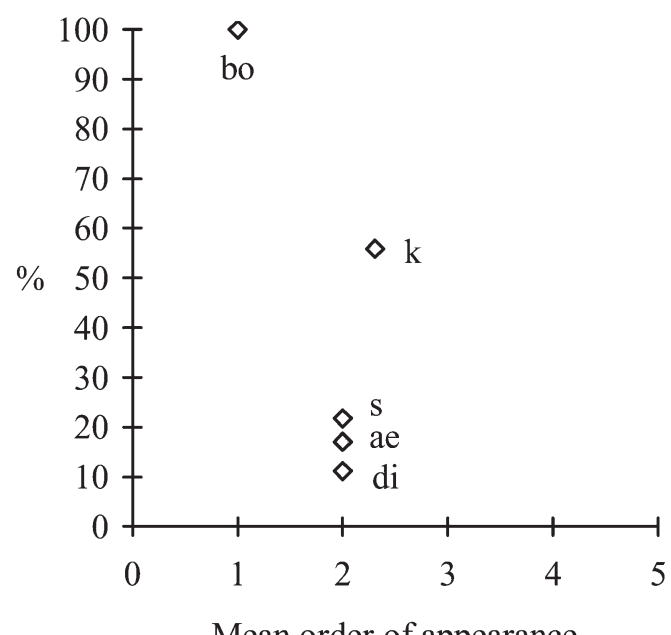

Mean order of appearance

7 yr-TV-free

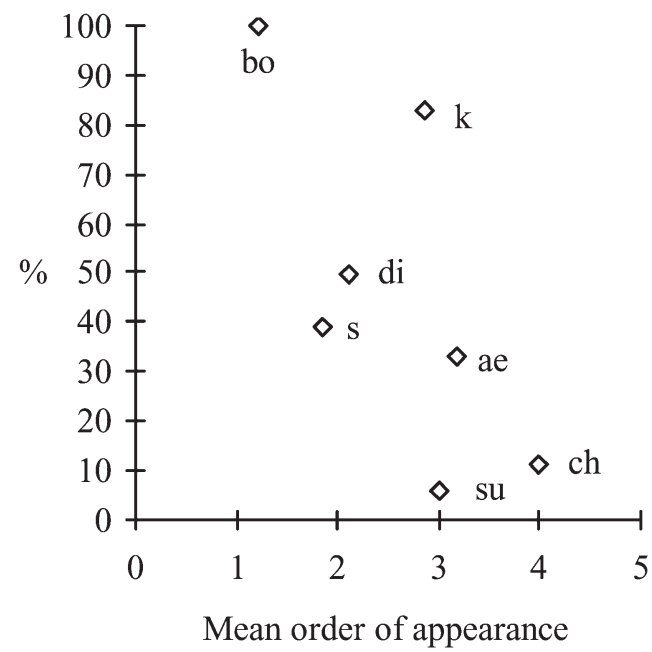

9 yr-TV-free

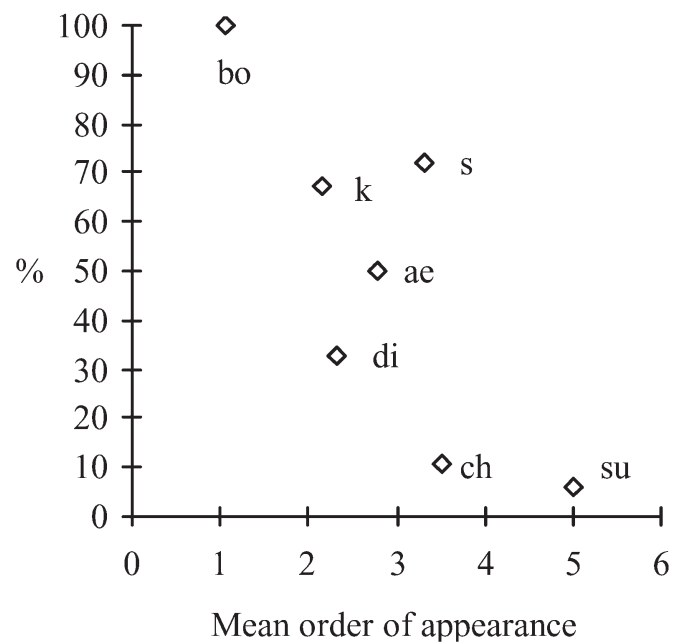

$5 \mathrm{yr}-\mathrm{TV}-\mathrm{copy}$

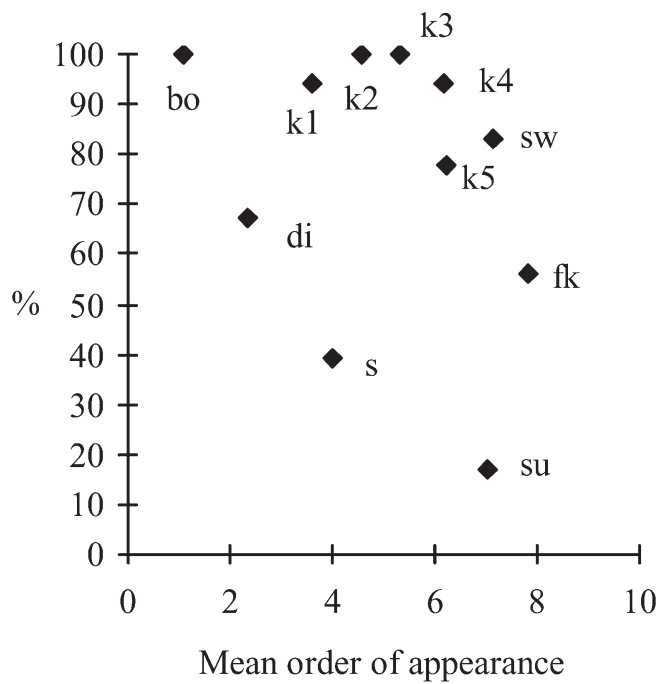

7 yr-TV-copy

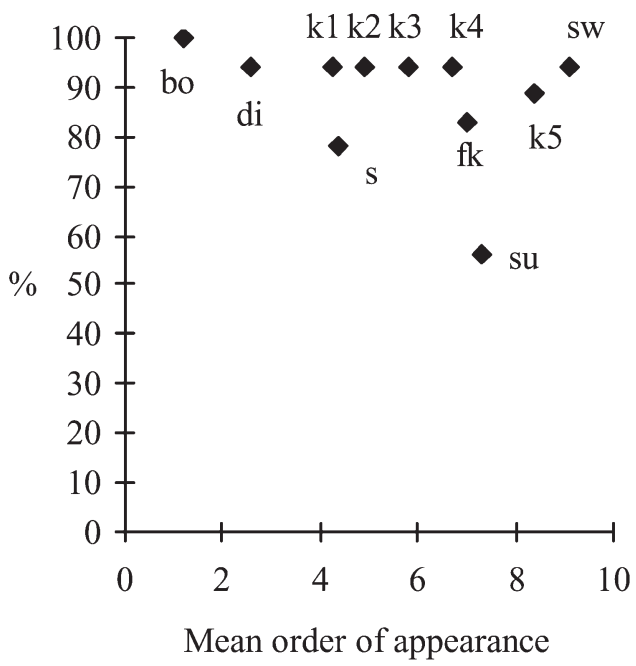

9 yr-TV-copy

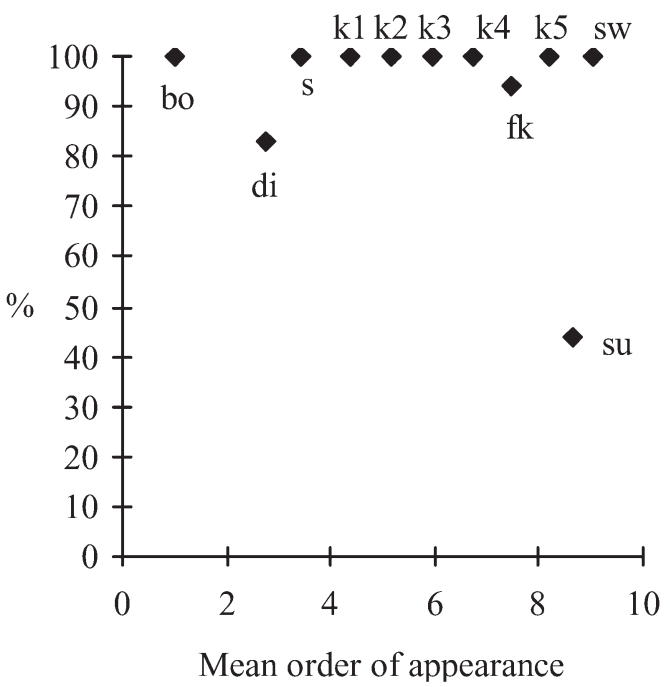

Figure 4. Relation between percentages of occurrence of the features of the television and their mean order of appearance in the drawing sequences per age group and task (see Appendix A for full data). 


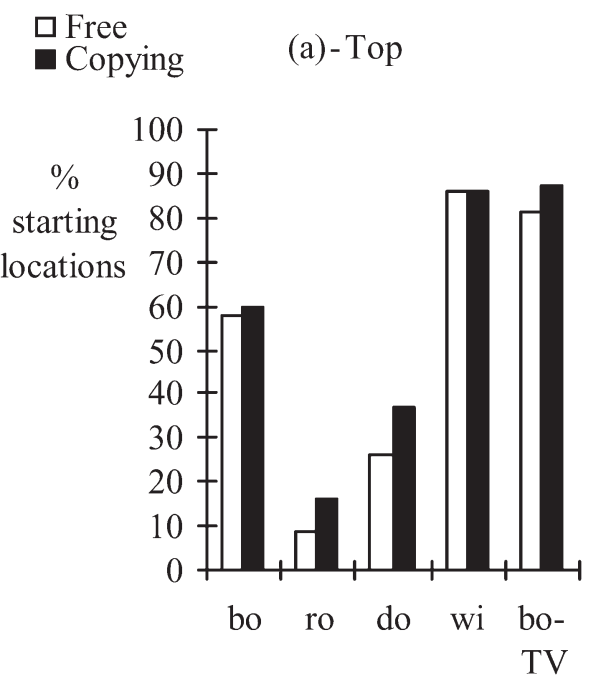
$\square$ Free
- Copying
(b) - Left

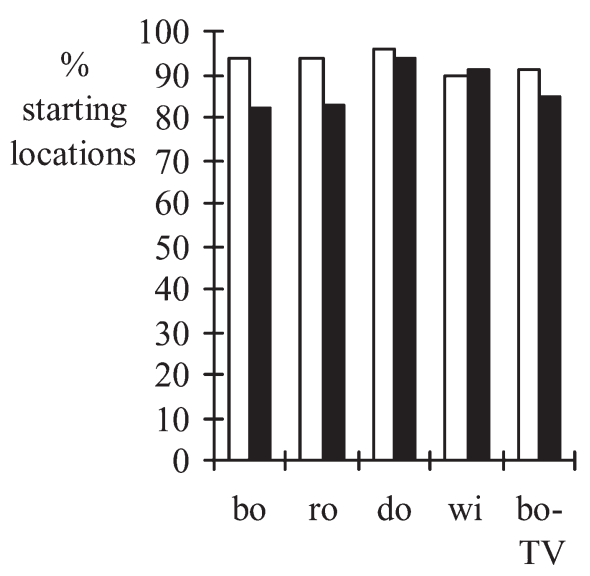

\author{
$\square 5$ years \\ 7 years \\ (c)-Vertical \\ 9 years
}

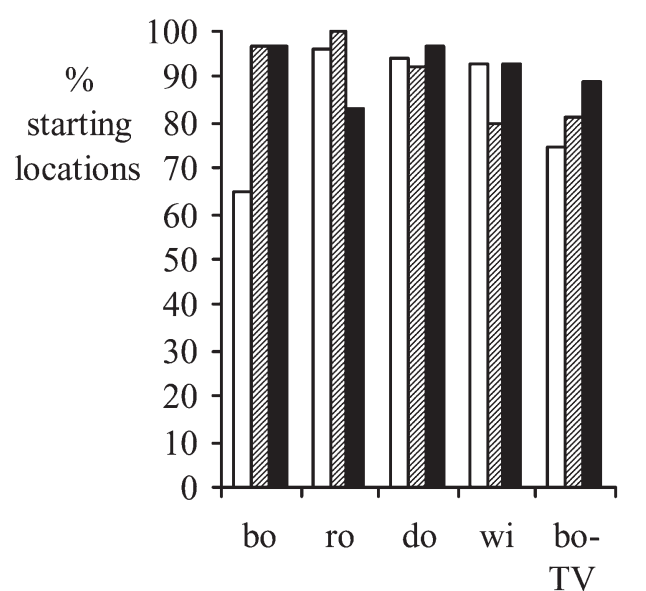

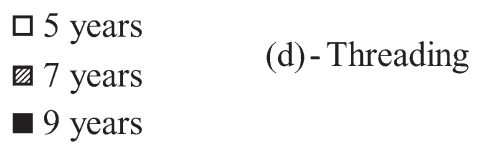

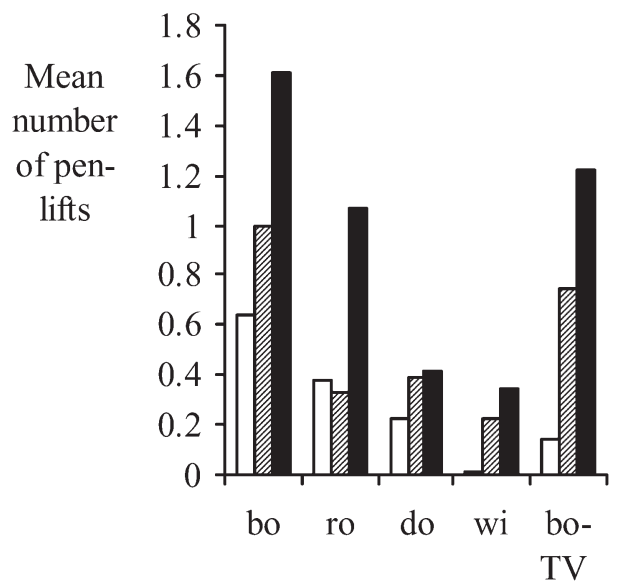

Figure 5. Mean percentage of application of the graphic rules, start top (a) and start left (b) as a function of core feature and task, start vertical (c) and threading (d) as a function of core feature and age.

the accretion principle led children to elaborate subsystems of features, namely the window subsystem (wi $->$ wi1, wi2, wi3), the door subsystem (do $->$ do1) and the chimney subsystem (chi $->$ chil). These subsystems were much more present at ages 7 and 9 than at age 5 . Because these subsystems associated a core with peripheral features (e.g., wi with wi1, wi2, wi2), it means that some peripheral features were produced before drawing other more generic features.

In the copying task, the complexity of the house model was largely ignored by the youngest children, who strongly tended to produce the core features of the object (body, roof, windows, door) in an order similar to that observed in the free drawing task. At ages 7 and 9, the children continued to draw the body and roof of the house first, but then tended to draw, by accretion, some peripheral features of the model, like the chimney (chi) or the gutter (gu), before drawing more generic features such as the windows (wi) and the door (do). Most of the peripheral features of the model were nevertheless relegated to the end of the drawing process. Sequences of production of the features of the television were much more heterogeneous, especially in the free context because of the variability in the nature of the drawn peripheral features (see Figure 4). Globally, however, a recurrent sequence organised the features from age 7 in the free drawing condition: "body $>$ screen $<->$ knobs $->$ support". Under the copying condition, a similar recurrent sequence was observed whatever the age (from body to internal features and to external ones).

Figure 5 presents the results relative to the application of graphic rules (starting top, starting left, with a vertical, and threading) in the production of the more frequently drawn features of the objects (body, roof, door and windows of the house and body of the television). A series of 3 (age) $\times 5$ (feature) $\times 2$ (task) mixed ANOVAs with both feature and task as within-subjects factors was performed on the frequency of use of each rule ${ }^{2}$. Sex was not a significant factor $(p s>.10)$.

\footnotetext{
${ }^{2}$ Several studies have shown that ANOVAs can be used with binary data (e.g., Gabrielson \& Seeger, 1971; Hsu \& Feld, 1969; Lunney, 1970).
} 
Table 4

Percentages of children showing conservation of start top/bottom, start left/right, start vertical/horizontal, and pen-lifts from the free task to the copying task as a function of age and core features

\begin{tabular}{|c|c|c|c|c|c|c|}
\hline & \multicolumn{6}{|c|}{ Core feature } \\
\hline & Body & Roof & Door & Window & Body-TV & Mean \\
\hline \multicolumn{7}{|c|}{ Start top/bottom conservation } \\
\hline 5 years & $61 \%$ & $83 \%$ & $94 \%$ & $67 \%$ & $72 \%$ & $76 \%$ \\
\hline 7 years & $83 \%$ & $89 \%$ & $61 \%$ & $72 \%$ & $94 \%$ & $80 \%$ \\
\hline 9 years & $94 \%$ & $67 \%$ & $89 \%$ & $72 \%$ & $83 \%$ & $81 \%$ \\
\hline \multicolumn{7}{|c|}{ Start left/right conservation } \\
\hline 5 years & $94 \%$ & $94 \%$ & $100 \%$ & $83 \%$ & $72 \%$ & $89 \%$ \\
\hline 7 years & $83 \%$ & $89 \%$ & $94 \%$ & $61 \%$ & $89 \%$ & $83 \%$ \\
\hline 9 years & $89 \%$ & $72 \%$ & $100 \%$ & $100 \%$ & $78 \%$ & $88 \%$ \\
\hline \multicolumn{7}{|c|}{ Start vertical/horizontal conservation } \\
\hline 5 years & $50 \%$ & $94 \%$ & $100 \%$ & $78 \%$ & $72 \%$ & $79 \%$ \\
\hline 7 years & $94 \%$ & $100 \%$ & $83 \%$ & $61 \%$ & $72 \%$ & $82 \%$ \\
\hline 9 years & $94 \%$ & $78 \%$ & $94 \%$ & $83 \%$ & $78 \%$ & $86 \%$ \\
\hline \multicolumn{7}{|c|}{ Pen-lifts conservation } \\
\hline 5 years & $56 \%$ & $72 \%$ & $89 \%$ & $94 \%$ & $83 \%$ & $79 \%$ \\
\hline 7 years & $50 \%$ & $67 \%$ & $56 \%$ & $72 \%$ & $50 \%$ & $59 \%$ \\
\hline 9 years & $17 \%$ & $39 \%$ & $78 \%$ & $61 \%$ & $44 \%$ & $48 \%$ \\
\hline
\end{tabular}

The start top principle (Figure 5a) applied in $54.7 \%$ of cases with no significant differences between the age groups, $F(2$, $51)=1.39, M S E=0.30, p=.25$. Its percentage of application did not vary significantly from task to task, $F(1,51)=3.40$, $M S E=0.09, p=.07$, but was strongly sensitive to the features, $F(4,204)=52.76, M S E=0.21, p<.001$. Post hoc analyses (Scheffé test) showed that this principle was largely observed for the drawing of the bodies (house and television) and of the windows, but few for the roof and door $(p<.01)$. Indeed, the top principle competed with the anchoring principle for the two last features, and the children tended to anchor the first drawn segment of these features to the house body, thus implying a bottom start.

Starting at left (Figure 5b) applied in $90.3 \%$ of cases with no significant differences between the age groups, $F(2,51)<1$, $M S E=0.37, p=.80$. This principle was applied less frequently in the copying task $(87 \%)$ than in the free one $(93 \%), F(1,51)=7.76, M S E=0.06, p<.01$. Note, however, that its high incidence demonstrated that the children's drawing behaviour was highly structured even when a model was available. Sensitivity of the start left principle to the features was not significant, $F(4,204)=1.83, M S E=$ $1.83, p=.12$.

Starting with a vertical (Figure 5c) applied in $89 \%$ of cases with no significant differences between the age groups, $F(2$, $51)=1.64, M S E=0.16, p=.20$. This principle was tasksensitive, $F(1,51)=11.41, \mathrm{MSE}=0.09, p<.01$ : It was applied less frequently in the copying $(84 \%)$ than in the free task (93\%), whatever the age. A significant effect of the feature, $F(4,204)=3.41, M S E=0.09, p<.05$, indicated that starting with a vertical was less frequently observed for the drawings of the bodies (house, television) than for the drawing of the other features. However, a significant interaction between age and feature, $F(8,204)=4.76, M S E=0.09, p$ $<.001$, indicated that this was due to the youngest children (post hoc Scheffé test, $p=.05$ ). Considering that these features usually had a horizontally oriented rectangular shape, it means that the youngest children tended to start with the longest segment.

The number of pen-lifts (Figure $5 \mathrm{~d}$ ) was age-sensitive, $F(2$, $51)=11.36, M S E=1.71, p<.001$ : It increased significantly between 5 and 9 years of age (post hoc Scheffé test, $p<.01$ ). It also varied as a function of the features, $F(4,204)=25.53$, $M S E=0.50, p<.001$, being higher for the bodies (house and television) and the roof than for the other features (post hoc Scheffé test, $p<.01)$. A significant age by feature interaction, $F(8,204)=3.61, M S E=0.50, p<.001$, revealed that the increase in pen-lifts between 5 and 9 years occurred only for the drawing of two types of features, the body of the house or the television (i.e., the largest features).

The above results demonstrate that, in both tasks, the drawing process was highly structured by the application of the graphic rules. Table 4 presents the percentages of children showing conservation, from the free task to the copying one, of starting positions (top/bottom and left/right), starting directions (vertical/horizontal), and threading (number of pen-lifts) per age group and features. A series of 3 (age) $\times 5$ (feature) mixed ANOVA with feature as a within-subjects factor was performed on the percentages.

Table 4 shows that, from the free task to the copying one, starting positions (top/bottom and left/right) and starting direction (vertical/horizontal) stayed highly constant with age in the production of the core features of the objects. Age introduced no significant effect on the percentage of conservation of top/bottom starting positions (mean $=79 \%), F(2,51)$ $<1, M S E=0.22, p=.70$, left/right starting positions (mean = $86.7 \%), F(2,51)<1, M S E=0.15, p=.59$, and vertical/ horizontal directions (mean $=82.3 \%), F(2,51)<1, M S E=$ $0.20, p=.60$. In contrast, the conservation of threading behaviour varied as a function of age, $F(2,51)=6.94, M S E=$ $0.32, p<.01$, being higher in the youngest children $(79 \%)$ than in the older age groups $(59 \%$ and $48 \%$ at ages 7 and 9 , respectively; post hoc Scheffé test, $p<.01$ ).

A significant effect of feature was obtained on the 
conservation of threading behaviour, $F(4,204)=6.08, M S E=$ $0.18, p<.001$. Results revealed that the door $(74 \%)$ and windows $(76 \%)$ of the house were more frequently drawn with the same number of pen-lifts than the other features (less than $59 \%$ ) (post hoc Scheffé test, $p<.05$ ). The interaction between age and feature was not significant, $F(8,204)=1.35$, $M S E=0.18, p=.22$. This means that the children were sensitive to the size of the features present in the proposed models, with the largest features leading the children to increase the number of pen-lifts during their productions. Furthermore, significant interactions between age and feature were obtained on the percentages of start top/bottom conservation, $F(8,204)=2.54, M S E=0.15, p<.05$, and start vertical/horizontal conservation, $F(8,204)=3.64, M S E$ $=0.12, p<.001$. Results indicated that the conservation of the starting point (top/bottom) was less pronounced at age 5 $(61 \%)$ than at age $9(94 \%)$ for the production of the body of the house (post hoc Scheffé test, $p<.05$ ), but not for the other features (post hoc Scheffé tests, $p>.94$ ). The same pattern of results applied to the conservation of starting direction (vertical/horizontal), which was lower at age 5 $(50 \%)$ than at age $9(94 \%)$ for the house body production (post hoc Scheffé test, $p<.05$ ), but not for the other features (post hoc Scheffé tests, $p>.38$ ). Modifications of the starting position and direction observed at age 5 for the house body drawing can be related to the fact that these children tended to start with the longest segment of the body (horizontal) when they had a model of a house at their disposal. When these children drew the house under the free condition, they preferentially started with the vertical segment of the body.

\section{Discussion}

In the literature on drawing, the notion of graphic formula has been employed to account for the syntactical aspects of the ongoing drawing activity and has been referred to as a stable sequencing of the features of a drawing (see, e.g., van Sommers, 1984; Zhi et al., 1997). In the present paper, we have focused on graphic formulas in a developmental perspective, hypothesising that the order of production of features of a given object reflects, in part, how this object is represented as a category in the child's conceptual system. We analysed children's (5, 7, 9 years) drawings of two different objects (a house and a television) in two different successive tasks (free drawing and copying task) in terms of categories, assuming that the frequency of occurrence of a given feature in children's drawings reflected its semantic weight. We then investigated the relations between percentages of occurrence and mean production ranks of features, to assess the extent to which a core-to-periphery progression principle (van Sommers, 1984) applied to the graphic formulas as a function of age, object, and task.

Content-based analyses of the drawings showed that the content of the free graphic representations did not differ from 5 to 9 years with respect to features with relatively similar weights, i.e., either those that defined the core of the graphic representations or the peripheral ones. Categorical definitions of the house and television appeared to be fairly stable across ages both in terms of identity and the number of features present in the drawings. Nevertheless, while the core features of the house (body, roof, door, windows) were sufficient to produce a minimal version of the category, this was not the case for the television (body only being a core feature). Thus, as suspected, this category was still in the process of being established by the children.

When children drew from photographic models (copying task), consideration of the specific features of the house model was more extensive at ages 7 and 9 than in the youngest children. The youngest children did not introduce many novel features in their house drawing in comparison with their spontaneous drawing of that object. This result shows that the differences obtained between both tasks cannot simply be due to a task order effect, according to which the previous free task could be thought of as a warm-up exercice for the copying task. With older children, changes observed from the free to the house copying condition were mainly related to an extension of the category in terms of peripheral features, not core features. We propose to relate these results to findings classically reported in categorical development; that the extension of a category mainly concerns the peripheral features of objects (Arcuri \& Girotto, 1986; Bjorklund, Thompson, \& Ornstein, 1983; Cordier, 1993). The availability of the television model resulted in an increase in the number of drawn features at all ages, so that the drawing produced under the copy condition included sufficient core (and peripheral) features of this object in terms of a category. This suggests that producing more detailed drawings can be induced by providing complex models, at least as long as the objects are not yet well established as categories in the child's conceptual system. Spontaneous drawings of objects that are well established as a conceptual category (namely, the house in our experiment) are open to an extension in terms of number of peripheral features, progressively with age, when complex models are provided.

Process-oriented analyses revealed close relations between the weight of a feature and its place in the drawing sequence: The more generic a feature, the earlier it was drawn. As expected, in the free drawing condition, the core-to-periphery progression principle was more relevant in accounting for the graphic formulas describing the house than those describing the television in the young children. These results may provide support for van Sommers' (1984) perspective, that the conceptual organisation of the object's features in terms of semantic weights plays a role in the sequencing of the features within the graphic formulas. The development of the object as a category in the child's conceptual system could be largely congruent with the development of the graphic formula used to depict that object. The house was well-established as a category in the young children's conceptual system (5 and 7 years) and graphic formulas used to depict that object were under the scope of a semantic force (core-to-periphery progression principle, van Sommers, 1984). With age, peripheral features of the house became more frequent and the semantic force interacted and competed with the accretion principle, resulting in a reorganisation of the graphic formula through the formation of subsystems of features (9 years). Contrary to the house, the television was still in the process of becoming established as a category in the 5-year-old child's conceptual system; in fact, the semantic force was principally evident in the older children's graphic formulas (7 and 9 years).

The core-to-periphery progression principle was less pronounced under the copying condition: This principle applied mainly to the house graphic formulas produced by the young children. In the copying task, the graphic formulas were much more open to the structuring influence of the accretion 
principle than they were in the free task: Subsystems of features were elaborated and some peripheral features were consequently produced before drawing other more generic features. Following van Sommers (1984), the graphic formula would emerge from possibly conflicting influences between different ordering principles, the semantic factor (core-to-periphery progression principle) and the geometrical factor (principle of accretion). Under copying conditions, the order of production of the features was under the influence of perceptual and geometric factors, which elicited the production of subsystems of features at the depends of the application of the core-toperiphery progression principle. In the copying task, the youngest children who largely ignored the complexity of the house model strongly tended to reproduce their spontaneous graphic formulas. In the older children, in contrast, extension of the category, following the copy of the house model, paralleled changes in the organisation of the graphic formulas (subsystems elaboration). Greater rigidity was thus found in the young children's graphic formulas of a conceptually established object (the house) than in those of the older age group. It can be suggested that the attainment of behavioural mastery in the drawing of a familiar object is initially associated with a certain rigidity, both procedural and representational (see Karmiloff-Smith, 1992; Picard \& Vinter, 1999).

However, a different account of these results could be suggested. Instead of illustrating the core-to-periphery progression principle, the more recurrent sequencing found in the house drawing, i.e. "body-roof-door or windows-peripheral features", may be explained by a process according to which children started from the largest elements, proceeding to the smallest ones. On this view, the logic of drawing progression would be mainly determined by perceptual attributes of the object such as its size, not by conceptual attributes. Of course, the application of the principle of accretion, as illustrated in a sequence like "body-roof [chimney-aerial]-door [handle-lock]-windows [shutters-curtains]-peripheral features" would undermine the influence of size. However, it would be most interesting to test in a further study the influence of the size of the features on the sequencing adopted by the drawers.

Analyses carried out on the local aspects of the drawing process showed that the children strongly applied graphic rules (starting top, starting left, with a vertical, and threading) when they produced the core features of the objects. This was true in both the free and copying tasks, though the degree of application of some rules (the start left and start vertical principles) was somewhat diminished in the copying condition. From one task to the next, we also found a high regularity of the actions related to starting positions, direction, and threading involved in the production of the core features of the objects. Much more conservatism was, however, observed in the youngest children's drawing process with regard to threading than in the other age groups. Application of the graphic rules was dependent on geometrical factors, notably concerning the size of the drawn features. For instance, the increase of threading behaviour with age was principally observed for the drawing of the largest features, and vertical starts were applied most frequently to the drawing of the longest segment of a graphic feature, especially in the young children. Interestingly, the graphic rules were also open to higher-order influences, such as the anchoring principle. In the case of conflicts, for instance between starting at the top and anchoring the roof to the previously drawn body, the children chose to anchor and thus had to start at the bottom (see also van Sommers, 1984).

To conclude, the present study provides some support to van Sommers' approach, according to which children's graphic formulas result from the concurrent influence of semantic and perceptual-geometric factors. The semantic force specifies feature production order with regard to their semantic weight for the representation (from core to peripheral features), while the perceptual-geometric force determines feature production order with regard to their spatial proximity (drawing by accretion). Our main contribution was to show that the development of the graphic formula used to depict an object could be in line with the development of that object as a category in the child's conceptual system. It should be noted, however, that the range of materials used in the present study was much restricted, both in terms of objects and features on which analyses were conducted. This consequently limits the generalisations of our data and suggests additional avenues to explore. The present study should be seen mainly as an exploratory experiment that hopefully may enhance further research on the development of graphic formulas in children. Whether our preliminary findings can account for a wider range of objects or can apply to children with specific impairments, such as blind children, could be a motive for further studies. Researchers (e.g., Heller, Kennedy, \& Joyner, 1995; Kennedy, 1993; Kennedy, Gabias, \& Nicholls, 1991; Millar, 1975) have shown that visually impaired children could portray familiar objects, such as the human figure, a horse, a bird, a cube or a table, with a raised line drawing kit. Moreover, these drawings shared strong similarities with drawings produced by sighted children. Kennedy et al. (1991, p. 263) suggested that "pictures are universals", being available to vision and touch. However, these interesting studies have mainly focused on the symbolic aspects of drawing. It is only recently that some attention has also been paid to the drawing process itself (D'Angiulli \& Maggi, 2003, 2004; Kennedy, 2003). If the development of graphic formulas used to depict an object parallels, at least partially, the development of that object as a category in a child's conceptual system, we may expect blind children to behave similarly to sighted children with respect to the "how" of drawing.

Manuscript received December 2003 Revised manuscript received April 2005

\section{References}

Arcuri, L., \& Girotto, V. (1986). Norme di tipicita per sei categorie naturali: Uno studio evolutivo. Giornale Italiano di Psicologia, 3, 409-443.

Arnheim, R. (1964). Art and visual perception. Berkeley, CA: University of California Press.

Barlow, C. M., Jolley, R. P., White, D. G., \& Galbraith, D. (2003). Rigidity in children's drawings and its relation with representational change. fournal of Experimental Child Psychology, 86, 124-152.

Berti, A. E., \& Freeman, N. H. (1997). Representational change in resources for pictorial innovations: A three-feature analysis. Cognitive Development, 12, 501522.

Bjorklund, D. F., Thompson, B. E., \& Ornstein, P. A. (1983). Development trends in children's typicality judgments. Behavior Research Methods and Instrumentation, 15, 350-356.

Cordier, F. (1993). Les représentations cognitives privilégiées: Typicalité et niveau de base. Lille, France: Presses Universitaires de Lille.

Cox, M. V. (1992). Children's drawings. Harmondsworth, UK: Penguin.

D'Angiulli, A., \& Maggi, S. (2003). Development of drawing abilities in a distinct population: Depiction of perceptual principles by three children with congenital total blindness. International fournal of Behavioral Development, 27, 193-200. 
D'Angiulli, A., \& Maggi, S. (2004). The depiction of car light beams in a child born completely blind. Perception, 33, 419-428.

Freeman, N. H. (1980). Strategies of representation in young children: Analysis of spatial skills and drawing processes. London: Academic Press.

Gabrielson, A., \& Seeger, P. (1971). Tests of significance in two-way desings (mixed models) with dichotomous data. British fournal of Mathematical and Statistical Psychology, 24, 111-116.

Goodnow, J., \& Levine, R. A. (1973). The "grammar of action": Sequence and syntax in children's copying behavior. Cognitive Psychology, 4, 82-98.

Heller, M. A., Kennedy, J. M., \& Joyner, T. D. (1995). Production and interpretation of pictures of houses by blind people. Perception, 24, 10491058.

Hsu, T., \& Feld, L. S. (1969). The effects of limitations on the number of criterion score values on the significance level of the $F$ test. American Education Research fournal, 6, 257-515.

Karmiloff-Smith, A. (1990). Constraints on representational change: Evidence from children's drawing. Cognition, 34, 57-83.

Karmiloff-Smith, A. (1992). Beyond modularity. A developmental perspective on cognitive science. Cambridge, MA: MIT Press.

Karmiloff-Smith, A. (1999). Taking development seriously. Human Development, 42, 325-327.

Kennedy, J. M. (1993). Drawing and the blind: Pictures to touch. Stanford, CT: Yale University Press.

Kennedy, J. M. (2003). Drawings from Gaia, a blind girl. Perception, 32, 321340 .

Kennedy, J. M., Gabias, P., \& Nicholls, A. (1991). Tactile pictures. In M. A. Heller \& W. Schiff (Eds.), The psychology of touch (pp. 263-299). Hillsdale, NJ: Lawrence Erlbaum Associates Inc.

Le Ny, J. F. (1979). La sémantique psychologique. Paris : PUF.

Lunney, G. H. (1970). Using analysis of variance with a dichotomous dependent variable: An empirical study. Fournal of Educational Measurement, 7, 239-263.
Millar, S. (1975). Visual experience or translation rules: Drawing the human figure by blind and sighted children. Perception, 4, 363-371.

Nihei, Y. (1983). Developmental change in covert principles for the organization of strokes in drawing and handwriting. Acta Psychologica, 54, 846-849.

Ninio, A., \& Lieblich, A. (1976). The grammar of action: Phrase structure in children's copying. Child Development, 47, 846-849.

Palmer, S. E., Rosch, E., \& Chase, P. (1981). Canonical perspective and the perception of objects. In J. Long \& A. Baddeley (Eds.), Attention and performance. Hillsdale, NJ: Lawrence Erbaum Associates Inc.

Picard, D., \& Vinter, A. (1999). Representational flexibility in children's drawings: Effects of age and verbal instructions. British fournal of Developmental Psychology, 17, 605-622.

Simner, M. L. (1981). The grammar of action and children's printing. Developmental Psychology, 17, 866-871.

Spensley, F., \& Taylor, J. (1999). The development of cognitive flexibility: Evidence from children's drawings. Human Development, 42, 300-324.

Stiles, J. (1995). The early use and development of graphic formulas: Two case study reports of graphic formula production by 2- to 3-year-old children. International fournal of Behavioral Development, 18, 127-149.

Thomassen, A. J. W., \& Teulings, H. L. (1979). The development of directional preference in writing movements. Visible Language, 13, 299-313.

van Sommers, P. (1984). Drawing and cognition: Descriptive and experimental studies of graphic production processes. Cambridge: Cambridge University Press.

Vinter, A. (1994). Hierarchy among graphic production rules: A developmental approach. In C. Faure, P. Keuss, G. Lorette, \& A. Vinter (Eds.), Advances in handwriting and drawing: A multidisciplinary approach. Paris: Europia.

Vinter, A. (1999). How meaning modifies drawing behaviour in children. Child Development, 70, 33-49.

Zhi, Z., Thomas, G. V., \& Robinson, E. J. (1997). Constraints on representational change: Drawing a man with two heads. British fournal of Developmental Psychology, 15, 275-290. 
Appendix A

Features list with their respective mean percentage of occurrence, mean order of appearance in the individual drawing sequences, and standard deviation (SD) for each age group

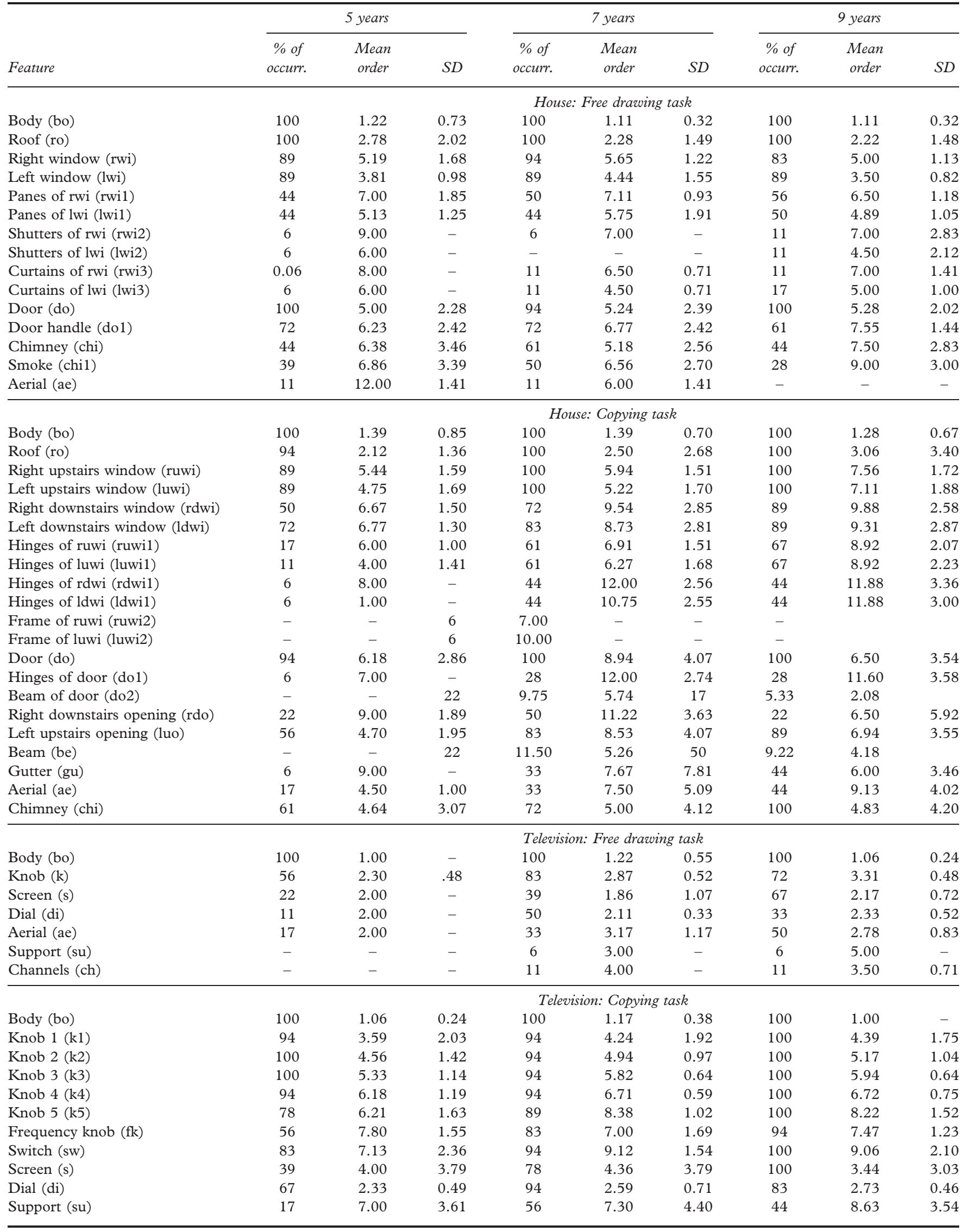

